\title{
The perception of the current provision of care for multiple sclerosis sufferers in the community
}

Marguerite Defriez Northwood Health Centre, North West London Hospitals NHS Trust, London, UK, Dorothy Griffiths The Management School, Imperial College, London, UK, Christopher Millett Imperial College School of Medicine, Kennedy Galton Centre, North West London NHS Trust, London, UK, Diviash Narendra Thakrar Northwood Health Centre, North West London Hospitals NHS Trust, London, UK, Melanie Winterbotham Mount Vernon Hospital, London, UK

\begin{abstract}
This multistakeholder study looked at the current provision of care for patients with multiple sclerosis (MS) within North Hillingdon, from the perspective of both the patient and the healthcare professional. Using in-depth interviews and focus groups, the study explored the patients' perception of their current care provision and unmet needs. Six main themes emerged from the research: lack of support at diagnosis; lack of information (both short and long term); social isolation; the impact on the family and carers; nonpresentation of other medical problems; inequality of access to care, and a lack of continued and co-ordinated care. The multidisciplinary focus groups and questionnaires carried out with hospital consultants, doctors, GPs, practice nurses, district nurses and physiotherapists echoed these themes. The main proposal that emerged from the data was to have an individual with expert skills and knowledge in managing MS, to be appointed at Primary Care Trust (PCT) level. This proposal would allow a best possible model of care to be offered to all patients with MS across a PCT, and in so doing meet demands of clinical governance.
\end{abstract}

Key words: chronic disease; multidisciplinary care; multiple sclerosis; nurse specialist; Primary Care Trust

\section{Introduction}

An extensive search of the literature suggested that very little research has been carried out hitherto on care of patients with low prevalence chronic conditions. The national prevalence of MS is one to two per 1000 of population (Robertson et al., 1996) making MS a low-incidence, low-prevalence chronic condition. MS is mainly managed in primary care. However, most GPs have few MS patients on their list so that patient contact tends to be infrequent. This can mean that keeping up to date with best practice and maintaining expertise in managing MS is difficult. A study comparing the health-related quality of life (HRQL) of

Address for correspondence: Marguerite Defriez, 31, Harford Drive, Watford, Herts WD17 3DQ, UK.

Email: defriez@btinternet.co.uk patients with MS and other chronic conditions in the community, such as epilepsy and diabetes, reported significantly worse HRQL among MS patients than among other groups (Hermann et al., 1996). A cross-sectional study of patients' and doctors' perception and assessments of disability in MS also found a disparity. Physicians were more concerned with physical manifestations of disease while patients were more concerned with quality of life issues such as vitality, mental and emotional health (Rothwell et al., 1997).

\section{Method}

This research project obtained ethics committee approval. We used participatory action research (PAR) as our method of enquiry, using semistructured interviews, focus groups, patient and doctor questionnaires. The origins of PAR can be 
traced back to the work of social scientists in the late 1940s. In action research the findings are fed directly back to the participants and the process is ongoing (Denscombe, 1998). The spiral of steps first outlined by Lewin (1946) involves identifying a problem, carrying out collaborative research, and feeding data back to the coparticipants, in a cyclical way. This allows data to be reflected on and analysed as the cycle progresses, and empowers coresearchers to be actively involved in the research process. This cycle of feedback/ analysis ensures the validity of the data. To achieve this feedback we fed our results back to patients and to the health professionals.

\section{Identifying potential participants}

Our initial step in the identification of potential participants was to write to all the GP practices (18) within North Hillingdon Primary Care Group outlining to them our project. A letter was sent to each individual GP, with copies to the practice manager and practice nurses. Practices that were willing to collaborate with our project were asked to carry out a database search to establish a disease register for their MS patients. Nine practices agreed to participate and contacted their MS patients enclosing details of our project and a consent form, which patients were asked to return to the lead researcher if they were willing to participate. They were also given a telephone number so that they could contact the lead researcher if they had any further queries.

Consent for contacting for interview was received from 20 patients, of whom 18 were eventually interviewed. These 18 patients were drawn from seven of the nine practices that had agreed to participate. Sixteen of the patients were interviewed at home and two at a health centre. Carers were present at six of the interviews and were keen to share their experience of being a carer. Two of the patients who had originally agreed to be interviewed subsequently decided not to participate, one because they were moving house and the other because of work pressure.

\section{Semi-structured interviews and research methodology}

We chose to use semi-structured interviews with MS patients as we felt that this method would allow patients the most effective voice. Totally unstructured interviews are not relevant in a context where specific questions are being raised. Conversely, a highly structured interview schedule would be too constraining in a situation in which we wanted to enable our respondents to develop their own direction of response.

The group decided that consistency in the interviewing was important, therefore two people from the group, the lead researcher and one other experienced researcher, undertook the interviews between them, using an agreed format. A pilot interview schedule was devised, and the interview prompts were agreed by the coresearchers (please see Appendix 1). The schedule and prompts covered a number of themes: the patient's story of their illness; their perception of the difficulties experienced in living with MS; sources of care/ support; their perception of the extent of communication between different healthcare professionals and with social services, and their views on improving the provision of MS services in the local population.

The interview format was piloted and then refined. Two further prompt questions were added, the first relating to the kind of follow-up that patients would like, the second relating to the usefulness of written information. With consent, the interviews were taped and transcribed. The material was coded so that the original text could be easily retrieved. Open questions were asked to allow for maximum interaction and the feedback of individual experiences. The average duration of the interviews was 1 hour (range $40 \mathrm{~min}$ to 2 hours).

While the sample size was small, we believe that it was representative as we felt that we had reached saturation point in collecting data from interviews (Glaser and Strauss, 1967) cited in DePoy and Gitlin (1993).

\section{Focus groups}

The aim of the focus groups was to hear people's experience of the management of MS patients and to see if there was any consensus on ways to improve the community care of MS patients within the Hillingdon area.

Focus groups can be seen as a form of group interview where group dynamics can enable people to explore issues and feelings which they may not have been able to articulate in one to one interviews (Kitzinger, 1995).

We initiated three focus groups. The first was 
conducted with three district nurses. The second was a multidisciplinary focus group, which included six GPs, one district nurse and three practice nurses. Taken together the participants in these focus groups represented six of the seven participant practices. The third was carried out with six patients who had MS, four females and two males. This focus group took place in a special MS centre where patients with all degrees of disability were catered for, and transport was provided. This enabled us to obtain views from patients across the range of disability. The facilitator for all of the focus groups used key themes that had emerged from the interviews to prompt where necessary, although in practice, the groups were quite vocal and interacted well. The nurses who participated stated that they did not feel intimidated by being in a multiprofessional group, and felt that they had an equal sense of power and voice (Hambridge, 2000). The focus groups were all taped and transcribed with consent from all participants.

\section{Patient and focus group participant questionnaires}

As part of the cyclical process in PAR, feedback was sent to all interviewees and focus group participants together with a questionnaire inviting comments and suggestions on our data and their emergent themes. We received eight replies from the 18 interviewees and six from the health professional focus group. Data received from this exercise were then collated with our previous data and analysed.

\section{Feedback to primary and secondary care}

A feedback meeting for primary care teams and local hospital staff was held at our local postgraduate centre. This provided us with the opportunity to present our research and to invite comments on our emerging themes and proposals. Handwritten notes of the discussion that took place were kept and the comments received were incorporated into our existing data.

\section{Qualitative analysis}

We did not feel that it was appropriate to use a software package such as NUDIST to analyse a relatively small sample such as ours. Rather, we reviewed the text for key concepts and key words.
Using these, we developed a coding framework for the texts of our interviews. This thematic analysis led to the identification of the six themes. These were:

1) Poor management of the diagnosis.

2) Inadequate access to information both short and long term.

3) A lack of co-ordinated and continued care.

4) The impact on the family and carers.

5) Nonpresentation of symptoms/problems seen as related to MS.

6) Lack of expertise amongst health professionals about MS.

These will be explored and illustrated by interviewee quotations in the results section, which follows.

\section{Results: Patient and focus group data}

\section{Theme 1: Poor management of the diagnosis}

Many of the interviewees had found the management of their diagnosis very distressing. This was true both for those patients who were newly diagnosed and for those who had been diagnosed many years previously. Owing to the difficulties involved in making a clinical diagnosis of MS, patients had undergone numerous tests and faced uncertainty and delay in receiving the results. For some the moment of diagnosis was a total shock:

Total shock, I heard the words MS on a ward round ... I thought I was better, I felt better, then on a ward round, that's how I found out I had MS and my world just shattered (17). When I burst into tears I assume the nurse, somebody must have called my husband to come in from the waiting room (17).

The older man stood at the door, but the younger man came and sat at the side of the bed .... and he told me ... that was a five minute thing and then they both left and I was on my own ... isolated there ... I began to cry and a young nurse came in, but that was really no support, she was a young nurse just settling in, and she was the person who came in as it were to support me you know, it wasn't great really (5). 
There also seemed to be reluctance on the part of professionals to tell patients bad news:

I was going through a lot of stress at work and I thought then I might be having a nervous breakdown, but um the way I found out was because I read it on a piece of paper, it said possible MS, and I went away and went back to work and I said to my boss, I think it said something about possible MS and she said phone the consultant and find out. So I spoke to the consultant and then he said, well it's a possibility so would you come back (2).

We also identified a number of examples of poor communication between professionals relating to what information had been given to the patient:

We went back to the GP, my leg is getting no better, Jim was holding the baby and she got his notes out and just asked him did he have MS? So they already knew but they had not told us, they said it was nothing to worry about. It all fell into place then, and the GP then tried to cover up her tracks, she realized we were not aware. (22)

Several participants recalled being told the diagnosis without a partner or friend being present:

And later - I think my husband should have been there and told the diagnosis with me ... I think more time should be given to the diagnosis, a family member could be there, like a husband or wife and um somebody to make it as positive as possible in the circumstances (5).

\section{Theme 2: Inadequate access to information}

Nearly all the interviewees stated that as far as they could remember, they had been given little information at the time of diagnosis or following the diagnosis. They would have liked written information on all aspects of the condition, including information relating to financial and practical help. Most of them had contacted the MS Society for information:

I was on my own, he was in his office and the conclusion was that I had MS, very very formal ... I was too shocked to ask for information I think, too shocked and confused (19).
I would have wanted information, first and foremost that you don't end up in a wheelchair necessarily, there is all different forms of MS (3).

The doctor tries to explain the best they can but they only have a certain amount of time really, you never see the same doctor (1)

\section{Theme 3: Lack of continued and co-ordinated care}

There was a general consensus that some of the care was not well co-ordinated, and communication between different departments and between professionals involved in the care was not always evident. The patients who required both nursing and personal care would have preferred one regular health professional to be responsible for their complete care:

What made it worse was every time I went there you saw a different doctor, and you'd have to go through the whole business again of telling them all how it started, it was a waste of time (22).

The carer: It's having somebody who overall looks at our care, when I asked about a social worker again, I was told she wasn't our social worker anymore, and when I said we must have somebody else I was told "oh no there is a lack of staff, and the district nurses and health visitors haven't got time" ... there is no one to overlook the whole thing (2).

\section{Theme 4: The Impact of MS on patients and their families}

All MS patients reported on the impact that MS had on their financial situation, on their family and friends, on mobility and consequent social isolation.

\section{Financial impacts}

Many of our interviewees had had to give up their jobs or take early retirement, due to their MS. Two patients, a beautician and a school teacher, complained of extreme fatigue, a librarian found that she became very clumsy and a mechanic found that every job took twice as long to perform. Two patients suffered balance problems and leg weak- 
ness while others mentioned the loss of their ability to drive and the difficulties posed in using public transport. Several patients were concerned about memory problems since developing MS. Those who continued working were doing so in a reduced capacity and often with great anxiety. Interviewees often reported experiencing great financial pressures:

The doctor wanted to sign me off but that doesn't help me because I've still got my mortgage to pay. I'm thinking about selling this house, pay the mortgage off and buy a smaller one without a mortgage if we can. We are discussing this now because I can't carry on, because sometimes if I don't get the work done properly ... I'm the kind of person I'm not going to charge the customer because its my fault, I couldn't do the job properly or I can't finish the job on time, it takes me twice as long to do a job than it used to do (20).

Financial independence made a great deal of difference to those who enjoyed it. It meant that they could afford to pay for housework, major adaptations to the house and the purchase of their own wheelchairs. Many of our sample and their carers were unaware of all their benefit and social service entitlements. Health professionals were not necessarily any better informed. This aggravated any financial and mobility/isolation problems experienced by a number of our sample.

Jim was on sick pay, I wasn't working, we didn't realize, we spent all our savings just on living until we had advice from the MS society (22).

\section{Effect on the family and friends}

Patients and their families and friends responded in different ways to MS. Many had experienced a breakdown in relationships following the diagnosis of MS, and one patient had lost contact with her daughter completely because of the daughter's fear that she would become responsible for looking after her mother. Sexual difficulties were also mentioned as a factor in causing relationship problems, but only one patient had been able to discuss this issue with a health professional. One patient admitted to feeling a failure since being diagnosed with MS and this loss of self-esteem had greatly affected her marriage.
Some patients had experienced positive support from family and friends, while others feared the reaction of friends and family as they felt they did not always understand their illness:

Look, I am the very same person that I always was, it's me, nothing has changed at all except for my legs, they're not operating normally but I am the very same person that I always was (5).

I haven't been able to lead a normal life with my children and my wife. It's just very frustrating, you can't do things that any normal family do (22).

My grandchildren have only ever seen me in the wheelchair. It's difficult to explain to the older one and the baby puts her arms up and I would love just to pick her up and I can't, it hurts (17).

The impact on carers of having a partner or relative with MS varied enormously. The majority of carers found that caring for someone with MS was time consuming and tiring. Many of those we interviewed had had to change their lifestyle. Several carers had retired early in order to care for their partners, and several others had moved house to accommodate their partner's needs. The patients with more severe disability were also concerned about the impact of the disease on their main carer:

My wife works so hard with work and then coming home and her day doesn't finish there, she comes home and starts again which is not fair. I mean I know she doesn't mind doing it, but I don't like seeing her have to do it (22).

\section{Mobility and social isolation}

Mobility is a critical issue as the disease progresses. Loss of mobility leads to a reduction in social contact and increasing isolation for the patient and sometimes the carer. Patients mentioned that friends and work colleagues tended to stop seeing them once they lost independent mobility. Social outings had to be planned carefully in advance especially with regard to access for wheelchairs, toilet facilities and the availability of a lift. One patient told us the story of how she attended a wedding at a hotel in London only to 
find that there was no lift to enable her to go to the reception:

There is no lift, not even a service one, the manager said we'll carry you up, ... in fact the bride and groom came down to see us and at one stage there were more people downstairs talking to us than there were upstairs at the reception (17).

\section{Theme 5: Nonpresentation of symptoms/problems} related to MS poorly managed

Each interview produced a very individual account of the development of the condition and the patient's experiences with health professionals. The progress and pattern of disease are difficult to predict, and both patients and professionals appeared to have been confused about which symptoms were attributable to MS and which were unrelated problems that could be treated. There also seemed to be nonpresentation or late presentation of some problems, which were then inadequately managed.

\section{Nonpresentation of problems}

Some very distressing and embarrassing problems such as urinary incontinence and sexual dysfunction were highlighted by several of the patients that we interviewed. The patients were reluctant to discuss these sensitive issues with friends or family and yet they found that health professionals did not raise these issues either, so there was an unnecessary delay in acknowledging and dealing with them. Four of the patients interviewed had suffered urinary incontinence and experienced poor management of the condition. One patient had received no help for a long time until she was hospitalized for another reason and a nurse taught her to catheterize:

The catheter was the best thing that ever happened because it made my life free again, because that's a terrible thing when you can't ... I had an accident and I didn't know that this was normal for MS people ... Oh that's very, very embarrassing, that is the worst thing. So now I've got it in, I don't like anyone knowing I've got a catheter (10).

Sexual relations are a sensitive issue that most patients will not request help with unless prompted to do so. The issue was not raised at most of the interviews, but one patient expressed his/her view:

I think your sex life is very important for everybody .... and that's one thing nobody discussed with you, not even your doctor or your neurologist ... we think there's nothing we can do, then we just cope as best as we can and that's why sometimes you see split ups and separations because we're human beings (20).

\section{Problems related to $M S$, which were poorly managed}

Pain has now been recognized as a disabling and often inadequately managed symptom in MS (Thompson, 1998), but patients still told us alarming stories:

I had terrible toothache, nobody told me that people with MS get neuralgia. So I went to the dentist and he X-rayed me and said there was nothing ... and I went to another dentist because the pain was so bad, and he injected seven teeth and did work on the eighth ... and then somebody said it might be neuralgia, so I go onto pills, it was magic, it cleared up (17).

In a similar case, a patient had pleaded with a dentist to remove a good tooth, which he eventually did:

and then I learnt from another patient that it could be trigeminal neuralgia due to the MS (22).

\section{Theme 6: Lack of expertise amongst health} professionals

Although the majority of patients valued their GP and found them supportive, there was a general feeling that most GPs did not have sufficient knowledge about MS:

I have a very good GP who puts herself out for me and is sympathetic to my needs, but she doesn't know anything about MS (22).

By and large most GPs don't really know much about MS ... They rather take the attitude that it means this, this or this and if you have other funny things they say well that's not MS, but of course I know it is ... I mean 
nobody's the same, that's one of the troubles isn't it really? (7)

Some of the patients liked to see a neurologist on a regular basis as they valued their expertise and liked the continuity of care they offered. A six monthly visit to see the consultant reduced their sense of isolation.

The confidence I think I get from the neurologist, I see him every six months, only for ten or fifteen minutes, but I do tell him that it's very useful to me to come and see him (5).

Many patients said they would like someone to contact, such as a nurse, who would understand their condition:

My GP doesn't know anything about MS, but an MS nurse would know what you go through. Why is there not an MS nurse in our area that we could get hold of? ... Someone that actually understands about MS itself and not just all the other neurological diseases (patient focus group)

\section{Views of the health professional stakeholders}

The district nurses who participated in the focus group would have liked earlier contact with MS patients to have time to get to know them and to establish rapport. Implementation of the objectives of The NHS and Community Care Act (1990) has increased the workload of community nurses, while The NHS plan (DoH, 2000) and the government response to the Royal Commission on Long Term Care (1999) have made a distinction between personal and nursing care. This has resulted in district nurses visiting patients with MS only if a nursing issue arises. Managerial and financial constraints would make it difficult for district nurses to take on more responsibility for patients with MS.

We held two sessions with consultants, hospital doctors, GPs and practice nurses, the first in focus group format early on in the research and the second as a discussion following the presentation of our findings from patients. The main themes from these focus groups mirrored those themes that had emerged from the patient interviews.

\section{Questionnaire data}

At the presentation session in addition to the discussion, 14 GPs were given a similar questionnaire to the one that we sent to all the interviewees. This had three sections:

1) How did the patient/health professionals feel about the provision of local care for MS patients.

2) What improvements might be made in service provision.

3) What were their views about the proposal for a specialist MS nurse.

\section{Provision of care in Hillingdon}

First, GPs were concerned that they could not do a great deal either for patients or their carers. They recognized that carers were under a lot of stress. Quite often carers were elderly and could not cope physically. Both patients and carers could feel lonely and isolated:

They reach this point where they can't cope out in the community, that's often a problem that precipitates admissions and emergencies and crises.

Carers suffer in silence a lot and even if we're in contact with carers and the patient, my experience is unless you actually probe gently and find out what the needs of the carers are they feel guilty about actually talking about their problem.

Social Services are over stretched in trying to provide individual care packages.

Respite and terminal care facilities are poor, and there is a lack of general education and knowledge about local facilities.

After assessment the patients are pretty much left on their own actually and when they come back ... they've got things, but I'm very limited in what I can say or do to help them.

Secondly, a need was expressed for somebody with the knowledge and the time to co-ordinate care for these patients:

Having somebody with the knowledge and time, or co-ordinating the time to keep these 
patients in touch and assess them as they go along and pull the services in.

A patient can feel that there is not a minute in the day that somebody is not coming through and it's not co-ordinated, everyone arrives at once and does the left hand know what the right hand's doing in that situation?

\section{Making improvements in Hillingdon}

From the focus group discussions and questionnaires two main themes emerged from all the stakeholders: access to counselling and the provision of an MS nurse.

\section{Access to counselling}

A need was identified for counselling at all stages of the disease process, for those having difficulty adjusting to the diagnosis through to those suffering from depression as the disease progressed. It was pointed out that there are specific problems that can arise which are related to specific issues and which arise at different ages, for example, the young women who are getting married, or individuals with relationship problems.

\section{Provision of an MS nurse}

The various stakeholders, independently, suggested a specialist health professional for MS patients and their carers. In the patients' focus group, a patient who had recently moved into the area from another London borough spoke about such a health professional whom he had found very helpful. In the second focus group (doctors and nurses) the suggestion arose following the example of a specialist nurse in Parkinson's disease.

Somebody who could access and co-ordinate all these things for people, like physiotherapy and occupational therapy or somebody who could tell people what's available or even just talk to them. Particularly, young chronically ill patients who get no service would also benefit from some central service.

The hospital consultants we interviewed also made this suggestion.

Communication is a huge worry, a specialist nurse has great merit.

MS is a very difficult disease, each patient is different in presentation and in the course of the disease. I support the idea of a nurse specialist. It has been very successful in diabetes care.

Similarly, with the GPs:

The interviews represent any chronic disease. Each GP never has enough people to really know. Those with chronic disability present with medical problems, but it is everyday problems that get them down.

There is too much emphasis on the medical model, not the caring model.

There is a need for more information about MS and how best to access or provide support/ care; for more rapid and more appropriate home assessment; and better specialist care and support, including occupational health and physiotherapy.

Local care is generally excellent, but an MS nurse and more complementary therapy should be available.

It was agreed that not every practice would have enough patients with MS to justify the support service for that practice but that over the whole area it was agreed that there would be sufficient MS patients who could benefit, as well as perhaps other patients with chronic disease.

It was felt that permanent funding rather than short-term funding should be found if a post for a MS specialist nurse was appointed, and it was generally felt that drug company sponsorship was not appropriate.

\section{Discussion}

This multistakeholder study explored the current provision of care in the community for people with MS in North Hillingdon. It also explored whether the recent formation of Primary Care Trusts in England provides new opportunities for the delivery of healthcare to individuals with low-incidence, low-prevalence, chronic conditions such as MS. Our findings suggest that people with MS appear to have considerable unmet needs at present. Six major themes were identified during interviews 
with stakeholders: poor management of the diagnosis; inadequate access to information; lack of continued and co-ordinated care; the impact of the disease on patients and their families; nonpresentation of symptoms/problems related to MS being poorly managed; lack of expertise among healthcare professionals. There was a clear consensus among all of the stakeholders in our study that it is extremely difficult for individual primary care practitioners to provide appropriate care to individuals with MS. This appears to be due to the infrequent contact that practitioners have with patients (due to the low prevalence of the condition), the wide spectrum of the clinical manifestations of the disease, the complexity of need and the need for multidisciplinary input. Both practitioners and individuals with MS felt that an additional resource was required to improve patient care. When pressed on what shape this resource would take, a number of stakeholders identified the need for a nurse specialist role.

This study has a number of limitations which need to be taken into account when considering the generalizability of our findings. The study was undertaken in a single and fairly small geographical area, so we cannot be sure that the issues identified in North Hillingdon are typical throughout the country. Our stakeholders were identified through volunteer practices, which may mean that we did not capture the full diversity of views available. However, we attempted to overcome this by employing a combination of qualitative and quantitative methods including semi-structured interviews, focus groups, questionnaires and presentation of our early findings to professional groups. This allowed us to develop both an indepth understanding of the main issues and also to give a wider audience of professionals and patients the opportunity to contribute to the research process by commenting on our emerging findings. We do feel that our patient stakeholders are fairly representative of individuals with MS given that they came from a range of social backgrounds and experienced very different levels of disease-related disability. One possible weakness of the data is however, the omission of a carers focus group.

The study has some important implications for implementing quality improvement in UK general practice for many low-prevalence, chronic conditions, which fall outside the current tranche of National Service Frameworks (NSF). While some of the issues identified in this study are specific to MS, much of the identified unmet need relates to broader issues around the lack of capacity in primary care to manage low incidence, yet complex disease. The new primary care arrangements provide PCTs with a new opportunity to tackle this. But how should they go about achieving this? Our findings suggest that primary care practitioners need to be supported through the deployment of some additional resource. The idea of a nurse specialist operating across a PCT was, as we have shown, widely endorsed by the stakeholders who contributed to this study. Most practitioners felt that the population covered by a PCT would give rise to an appropriate caseload of approximately 300-400 patients (given the prevalence of MS and assuming a PCT population of 200000 ). This complements the view of the patients in our study, who felt that they would like someone with expertise in MS who would better understand, coordinate and manage their care. It was clear from the interviews that a need exists for more information and support for MS patients and their carers, not only at diagnosis but at all stages of the disease. The nurse specialist could be a resource for sufferers of MS, their carers and health professionals. He/she could have an important teaching and education role, so that health professionals could develop their knowledge of MS and be better able to manage their caseload, while sufferers of MS could be given more information about their disease. The nurse specialist could also facilitate closer liaison between patients and health professionals, ensuring improved co-ordination and management of care. Ongoing research and audit of the post would be important.

This approach appears to have a great deal of merit, although it raises some difficult questions around equity. For example, should all low prevalence, chronic conditions receive this type of input? What is an appropriate caseload for such a position and will all patients benefit from this service? In any case, given the resource constraints of PCTs and their methods of working, such a role may not be realistic. Other possibilities could be to realign the responsibilities of district nurses or for PCTs to have a dedicated individual, as part of their clinical governance team, who has responsibility for clinical governance for low prevalence (nonNSF) conditions such as MS. This role could also help to ensure that frontline staff are kept up 
to date with best practice and that care is better coordinated between the primary and secondary sector.

Primary Care Trusts clearly now have an opportunity and, given their responsibilities around clinical governance, an obligation to improve the quality of care for individuals with nonNSF conditions. This paper has demonstrated a great deal of unmet need for individuals with MS in a West London Primary Care Group. We contend that this situation is not atypical for MS patients in general nor for individuals with other uncommon and complex health problems. We believe that PCTs should consider the challenges and options which their creation offers to bring about real improvements in patient care in this area.

\section{Acknowledgements}

Thank you to all the GPs, practice nurses, district nurses, practice managers, hospital consultants and physiotherapists who helped us in this project. Also, thank you to all the patients with MS and their carers whose participation made this study possible.

To West London Research Network (WeLReN) for their funding of this project and for their invaluable support.

\section{References}

Denscombe, M. 1992: The good research guide for small scale social research projects. Buckingham: Open University Press.

Department of Health 2000: The NHS Plan. London: HMSO.

DePoy, E. and Gitlin, L. 1993: Introduction to research. Mosby, 266-72.

Hambridge, K. 2000: Action research. Professional Nurse 15, 598-601.

Herman, B., Vickrey, B., Hays, R., Cramer, J., Devinsky, O., Meador, K., Perrine, K., Myers, L. and Ellison, G. 1996: A comparison of health related quality of life in patients with epilepsy, diabetes, and multiple sclerosis. Epilepsy Research 25, 113-18.

Hohol, M.J. Orav, E.J. and Weiner, H.L. 1995: Disease steps in multiple sclerosis: a simple approach to evaluate disease progression. Neurology 45, 251-55.

HMSO 1990: The NHS and Community Care Act 1990. London: HMSO.

Kitzinger, J. 1995: Introducing focus groups. British Medical research Journal 311, 299-301.
Lewin, K. 1946: Action research and minority problems. Journal of Social Issues 2, 41-56.

Robertson, N., Deans, J., Fraser, M. and Compston, D.A. 1996: Multiple sclerosis in south Cambridgeshire: incidence and prevalence based on a district register. Journal of Epidemiology and Community Health 50, 274-79.

Rothwell, P., Dowell, Z., Wong, P. and Dorman, J. 1997: Doctors and patients don't agree: cross sectional study of patient's and doctors' perception and assessments of disability in multiple sclerosis. British Medical Joournal 314, 1580-84.

Royal Commission on Long Term Care 1999: With respect to old age: long term care - rights and responsibilities. London: HMSO.

Thompson, A. 1998: Symptomatic treatment in multiple sclerosis. Current Opinion in Neurology 11, 305-309.

\section{Appendix 1: Interview prompts}

What does MS mean to you as a diagnosis?

What sort of treatment have you had?

What type of support services have you had? i.e., social services, friends

Which of these have been helpful?

Which have not been that helpful?

Who do you see on a regular basis?

What kind of follow-up would you like?

Where do you get most of your information?

What sort of things do you want information about?

Do you feel that some of the different people involved in your care communicate, so that each knows how you are doing at different stages?

How did you feel when you were diagnosed with your illness?

Can anything be done to make this moment less difficult?

Could this have been handled differently?

What sort of effect has your illness had on your family?

What is the hardest to come to terms with?

How do you feel in yourself at present physically and emotionally?

What is the difference in a good day and a bad day?

What makes you feel well?

What is the most difficult problem with your illness at the moment?

Is there any way that services can be improved?

Do you have any questions? 


\section{Appendix 2: Disability scale (Hohol et al., 1995)}

The table outlines the number of patients from each group

\begin{tabular}{lll}
\hline $\begin{array}{l}\text { Disability } \\
\text { scale }\end{array}$ & Level of disability & $\begin{array}{l}\text { No. of } \\
\text { patients }\end{array}$ \\
\hline 0 & Normal & 3 \\
1 & Mild & 1 \\
2 & Moderate & 1 \\
3 & Early cane use & 3 \\
4 & Late cane - dependent use & 1 \\
5 & Bilateral support & 1 \\
6 & Wheelchair bound & 5 \\
7 & Bedbound & 3 \\
\hline
\end{tabular}

\section{Appendix 3: Patient interviews and emerging themes}

\begin{tabular}{|c|c|c|c|c|c|c|}
\hline Interview & Diagnosis & $\begin{array}{l}\text { Lack of } \\
\text { information }\end{array}$ & $\begin{array}{l}\text { Co-ordinated } \\
\text { care }\end{array}$ & $\begin{array}{l}\text { Impact on } \\
\text { family/carers }\end{array}$ & $\begin{array}{l}\text { Nonpresentation } \\
\text { of problems }\end{array}$ & $\begin{array}{l}\text { Lack of } \\
\text { expertise }\end{array}$ \\
\hline 1 & Yes & Yes & Yes & Yes & - & - \\
\hline 2 & Yes & Yes & Yes & Yes & - & Yes \\
\hline 3 & Yes & Yes & - & Yes & - & Yes \\
\hline 4 & Yes & Yes & Yes & Yes & Yes & Yes \\
\hline 5 & - & Yes & - & Yes & - & - \\
\hline 6 & Yes & Yes & - & Yes & - & - \\
\hline 7 & Yes & Yes & - & Yes & - & - \\
\hline 8 & Yes & Yes & - & Yes & - & - \\
\hline 9 & Yes & Yes & - & Yes & - & Yes \\
\hline 10 & - & - & - & Yes & - & - \\
\hline 11 & - & - & - & Yes & Yes & - \\
\hline 12 & Yes & Yes & - & Yes & Yes & - \\
\hline 13 & Yes & Yes & - & Yes & Yes & - \\
\hline 14 & Yes & Yes & - & Yes & Yes & Yes \\
\hline 15 & Yes & Yes & - & Yes & - & - \\
\hline 16 & - & Yes & - & Yes & Yes & - \\
\hline 17 & Yes & Yes & Yes & Yes & Yes & - \\
\hline 18 & Yes & Yes & Yes & Yes & - & - \\
\hline
\end{tabular}

